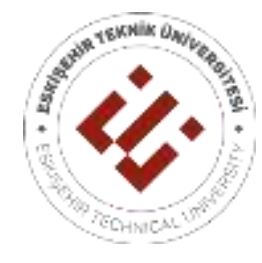

ESKISSEHIR TECHNICAL UNIVERSITY JOURNAL OF SCIENCE AND TECHNOLOGY A- APPLIED SCIENCES AND ENGINEERING

8th International Fiber and Polymer Research Symposium

(8th ULPAS) - Special Issue 2021

2021, Vol.22 pp. 39-50, DOI:10.18038/estubtda.979819

\title{
ENHANCING UV PROTECTION AND HYDROPHOBIC ABILITIES OF POLYESTER TEXTILES BY NOVEL SURFACE MODIFICATION TECHNIQUES
}

\author{
Ali AKPEK ${ }^{1, *}$ \\ ${ }^{\mathbf{1}}$ Department of Biomedical Engineering, Faculty of Electric and Electronic, Yildiz Technical University, Istanbul, Turkey
}

\begin{abstract}
In this study, water vapour permeability, wrinkle recovery, UV protection and contact angle properties of ion implanted Polyester (PES) fabrics were investigated. In order to achieve this goal; a Metal Vapor Vacuum Arc (MEVVA) source implanted $\mathrm{Pb}, \mathrm{Ag}, \mathrm{Ag}+\mathrm{N}, \mathrm{Ti}+\mathrm{O}$ and $\mathrm{Cr}+\mathrm{O}$ to the $\mathrm{PES}$ fabrics with $5 \times 10^{16} \mathrm{ion} / \mathrm{cm}^{2}$ and $30 \mathrm{kV}$ acceleration voltage. The test results were compared with unimplanted PES fabric. The results indicated that UV Protection and contact angle values increased significantly and also almost no change observed at water vapour permeability and wrinkle recovery. These results also varied on severly with different ion species.
\end{abstract}

Keywords: Ion implantation, Wrinkle recovery, UV Protection, Hydrophobia, Contact angle

\section{INTRODUCTION}

The textile industry is on crisis. Continuos seek for a lower cost and environmentally friendly manufacturing methods are still not satisfactory enough. There are several promising techniques are being utilized to create products with higher quality, higher performance, special abilities and longer life span. Surface modification of textiles appears to be a good solution for all these problems. The surface treatments that alters any desired specifications of the textile surfaces without harming them will provide great benefits for all humankind [1].

For this reason, new methodologies are investigated to modify textiles with special abilities. It is obviously understood that one of these methodologies is one step ahead then all other techniques. This technique is called ion beam implantation technology.

Metal Vapour Vacuum Arc (MEVVA) appears to be one of the most effective surface modification technology available nowadays [1]. In this study, MEVVA was used for surface enhancement.

Ion implantation is a novel technique that enhances the surface properties of any selected materials. Ion implantation can especially be useful for the surfaces of the materials which can also have capability to upgrade the textile products from conventional textiles to smart textiles [2].

Ion implantation has been evaluated for several materials [3-12]. However, the textile applications are still very limited. In this study, MEVVA ion implantation technique was applied to textile surfaces in order to provide them UV resistance, hydrophobia, water vapour permeability and wrinkle recovery abilities.

*Corresponding Author: aliakpek@yildiz.edu.tr

Received: 03.08.2021 Published: 30.11.2021 


\section{EXPERIMENTAL}

\subsection{Ion implantation of polyester fabrics}

A Metal Vapour Vacuum Arc (MEVVA) type of ion implantation system was used for Polyester (PES) fabrics [1]. In this study, MEVVA ion source implanted $\mathrm{Pb}, \mathrm{Ag}, \mathrm{Ag}+\mathrm{N}, \mathrm{Ti}+\mathrm{O}$ or $\mathrm{Cr}+\mathrm{O}$ to the polyester fabrics with $5 \times 10^{16} \mathrm{ion} / \mathrm{cm}^{2}$ and $30 \mathrm{kV}$ acceleration voltage. Each ion species was implanted to a different $10 \times 10 \mathrm{~cm}^{2}$ sized $100 \%$ polyester fabric. From now on, the word polyester will refer $100 \%$ polyester fabric.

The ions penetration depth depends on several factors such as the energy level of the ions, ion doses, ion species, ion flux and the atom density in the substrate [13].

\subsection{Water Vapor Permeability Test}

The analysis of water vapor transport properties of textile materials are important in this study. Water vapor permeability tests provide measurable informations about the comfort properties of textiles. In this test ASTM F2298-03(2009)e1 Standard Test Methods for Water Vapor Diffusion Resistance and Air Flow Resistance of Clothing Materials Using the Dynamic Moisture Permeation Cell test methodology was used to determine water vapor permeability. [14]

\subsection{Wrinkle Recovery Angle Test}

Analysis of wrinkle recovery is also a very important parameter in this study since it provides information about either MEVVA harms the textiles or not. Wrinkle recovery tester is used to investigate the wrinkle structures of polyester fabrics. Tests were done according to the AATCC 128 Wrinkle Recovery of Fabrics: Appearance Method test methodology [15].

\subsection{UV Protection Factor Test}

UPF Protection factor test will provide the information of either MEVVA has capability to provide special abilities to textile materials or not. This test measured the amount of blocked and transmitted ultraviolet radiation on textile materials. The blocked percentage of UVA and UVB radiation is calculated according to AATCC Test Method 183-2004 Transmittance or Blocking of Erythemally Weighted Ultraviolet Radiation through Fabrics [16]. In order to achieve that a spectrophotometer is utilized. Spectrophotometer analyzed the transmittance of UV radiation in this study.

Table 1. UV Protection Factor(UPF) Categories.

\begin{tabular}{ll} 
UPF Categories & $(\boldsymbol{\%})$ UV Permeability \\
\hline 15-24 Protection & $6.7-4.2$ \\
25-39 very well protection & $4.1-2.6$ \\
40-50, 50+ perfect protection & $<2.5$ \\
\hline
\end{tabular}



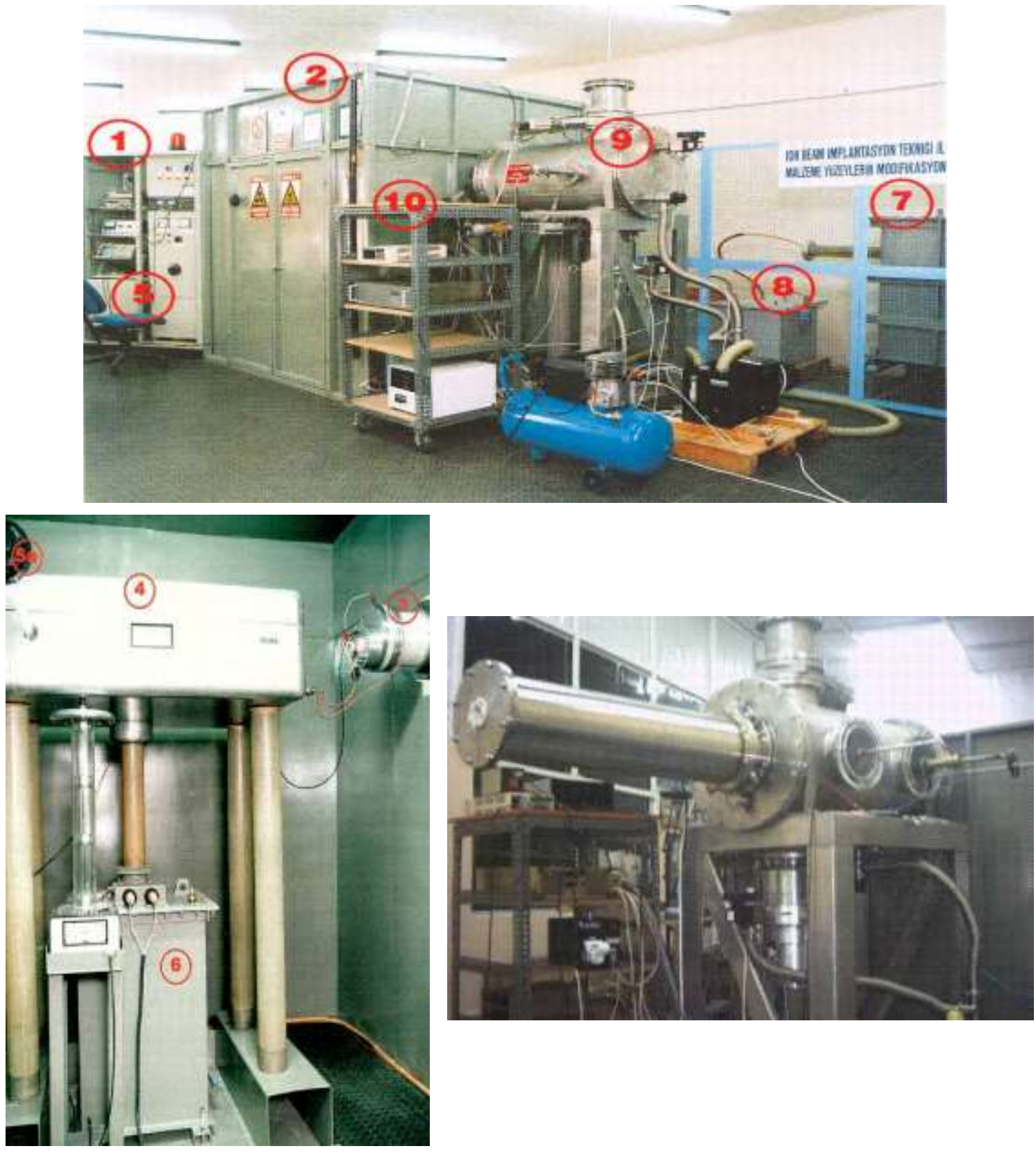

Figure 1. MEVVA Ion implantation Unit, (1) Control Panel, (2) Faraday Cage, (3) MEVVA Ion source, (4) Electrical supply circuit, (5) Charge control unit, (7), (8) Power supply, (9) Vacuum chamber

\subsection{Contact Angle Test}

This test was used to evaluate the fabric's capability of wetting by a standardized solutions with different surface tensions. In this work, standard drops of test liquids applied to polyester surfaces and observed for contact angle. The test methodology used in this test was AATCC 193-2004 Aqueous Liquid Repellency: Water/Alcohol Solution Resistance Test [17].

To compare success of each ion species at each test more efficiently, a success rate system was developed. This success rates were calculated with following formula

$$
S R=[(100 x B) / A]
$$


$\mathrm{SR}=$ Success rate,

$\mathrm{B}=$ Test result of selected ion species,

$\mathrm{A}=$ Test result of unimplanted polyester fabric.

For contact angle success rate; $A=35$, for UPF success rate; $A=3,87$ and for WRA success rate; $A=296$. These results are presented at Table 2. Detailed results were investigated in the following figures.

\section{RESULTS AND DISCUSSION}

After executing all the tests, the following table was resulted. All tests were achieved three times in order to obtain statistically meaningful results. The results presented below are arithmetic means of the experiments.

Table 2. All results obtained from the tests

\begin{tabular}{cccccc} 
No & $\begin{array}{c}\text { Water Vapor } \\
\text { Permeability } \\
\text { (WVP) }\end{array}$ & $\begin{array}{c}\text { Water Vapor } \\
\text { Permeability } \\
\text { Index (L) } \%\end{array}$ & $\begin{array}{c}\text { Wrinkle } \\
\text { recovery angle } \\
\left(\mathbf{W R A}^{\mathbf{0}}(\mathbf{W}+\mathbf{F})\right)\end{array}$ & $\begin{array}{c}\text { UV } \\
\text { Protection } \\
\text { Factor } \\
(\mathbf{U P F})\end{array}$ & $\begin{array}{c}\text { Contact } \\
\text { Angle } \\
\left.\mathbf{(}^{\mathbf{*}}\right)\end{array}$ \\
\hline Unimplanted & 546,6 & $109 \%$ & $296^{\mathbf{0}}$ & 3,87 & 35 \\
$\mathbf{P b}$ & 394 & $95 \%$ & $307^{\circ}$ & 15 & 111,68 \\
$\mathbf{A g}$ & 434,9 & $87,3 \%$ & $281^{\circ}$ & 30 & 113,32 \\
$\mathbf{A g + N}$ & 524,3 & $105 \%$ & $303^{\circ}$ & 10 & 123,87 \\
$\mathbf{T i + O}$ & 524 & $105 \%$ & $284^{\circ}$ & 10 & 125,05 \\
$\mathbf{C r + 0}$ & 451 & $90,7 \%$ & $285^{\circ}$ & 20 & 100,69 \\
\hline
\end{tabular}

Two tests were realized in order to understand ion implanted polyester fabric's UV Protection and hydrophobia abilities. One was UPF test and the other was contact angle test. On the other hand, two tests were also realized to understand if there had been any degredation formed after the ion implantation, One was water vapor permeability test and the other was wrinkle recovery angle test. The reason for performing these tests to fabrics was if there had been any degredation on fabrics, the results of WVP and WRA tests would have been changed significantly when compared with unimplanted polyester fabric. However no significant change observed at any implanted polyester fabrics. This may prove that MEVVA ion implantation causes no deformation on the surfaces of polyester fabrics. Further experiments are necessary to prove this claim.

UPF and contact angle test results are very promising. At UPF test, when compared with unimplanted polyester, especially $\mathrm{Ag}$ and $\mathrm{Cr}+\mathrm{O}$ implanted polyesters resulted with high efficencies. Also, at contact angle test, all implanted polyesters presented at least 3 times higher efficiencies when compared with untreated polyester fabric.

\subsection{SUCCESS RATES OF THE TESTS}

When contact angle test was analysed, it is obviously understood that ion implanted fabrics has shown distinctive success. This means polyester fabrics had become more hydrophobic after implantation. The highest success was seen at Ti+O implantation, it has presented 3.57 times higher hydrophobia after implantation. The least success was shown at $\mathrm{Cr}+\mathrm{O}$ ion implantation and even at that situation, it has presented 2,87 times higher hydrophobia when compared with unimplanted polyester fabric. 
Akpek / Eskişehir Technical Univ. J. of Sci. and Tech. A-Appl. Sci. and Eng. Vol. $22-2021$ 8th ULPAS - Special Issue 2021

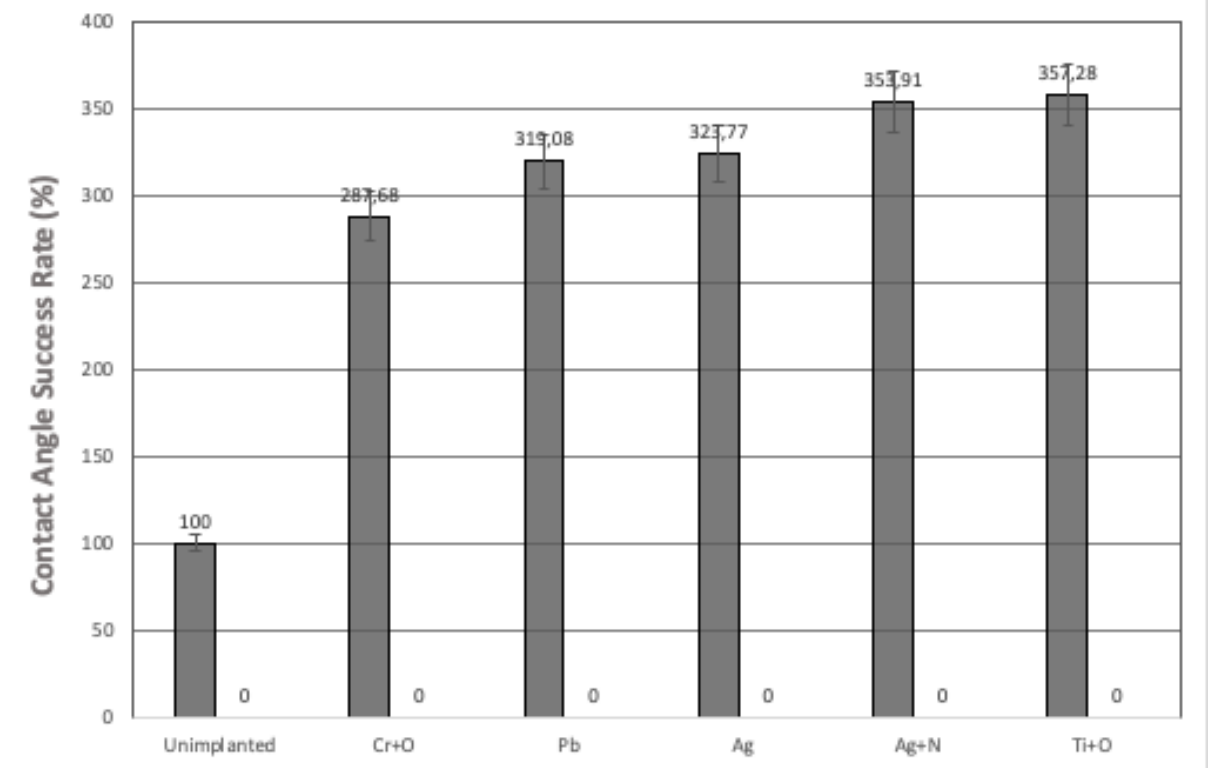

Figure 2. Contact angle success rate results of the ion implanted and unimplanted polyester fabrics

In this test, more contact angle success rate means more hydrophobia and more hydrophobia means more liquid repellent. Finally this means; less stains on textiles, less laundry, less electricity consumption, less detergant consumption, improved life-time for textiles, less textile production and a result with a more cleaner world. Original test results can be seen at Table 1.

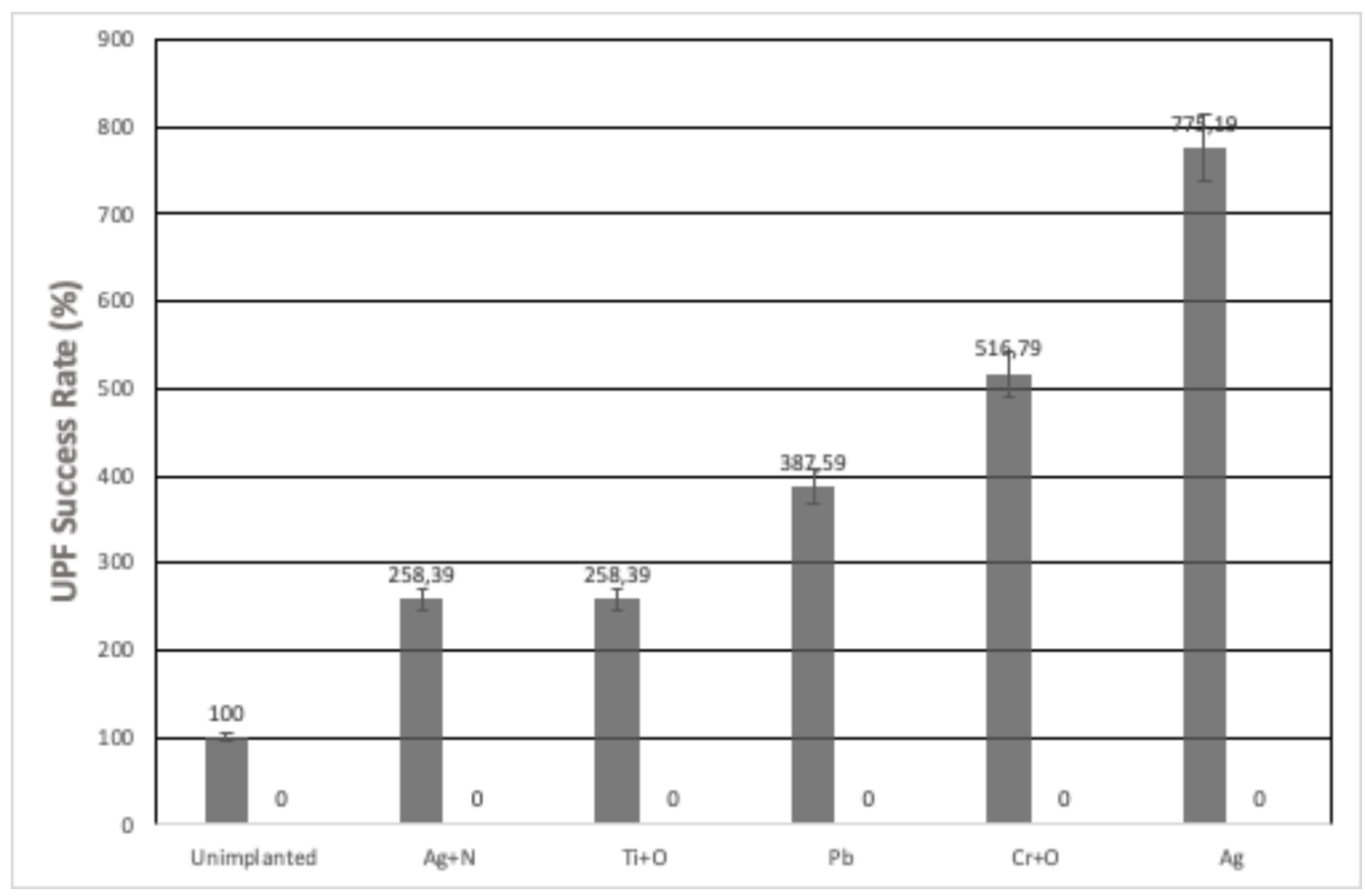

Figure 3. UV Protection Factor success rate results of ion implanted and unimplanted polyester fabrics

When UPF test analysed, it has been seen that ion implanted fabrics has presented the best results of the study. Especially Ag ion implanted polyester fabric has increased it's UPF value 775,19\% higher when compared with unimplanted polyester fabric. Even the least successful $\mathrm{Ag}+\mathrm{N}$ implantation has presented 
$258,39 \%$ increase it's UPF value. These results has proved us great benefits of MEVVA ion implantation for textile industry. Original test results can be seen at Table 2 .

\subsection{SUCCESS RATE OF CONTROL TESTS}

Table 3: Water Vapor Permeability Test results.

\begin{tabular}{lll} 
No & Water Vapor Permeability (WVP) & Water Vapor Permeability Index (L)\% \\
\hline Unimplanted & 546,6 & $109 \%$ \\
$\mathbf{P b}$ & 394 & $95 \%$ \\
$\mathbf{A g}$ & 434,9 & $87,3 \%$ \\
$\mathbf{A g}+\mathbf{N}$ & 524,3 & $105 \%$ \\
$\mathbf{T i}+\mathbf{O}$ & 524 & $105 \%$ \\
$\mathbf{C r}+\mathbf{0}$ & 451 & $90,7 \%$ \\
\hline
\end{tabular}

When WVP tests resulted, it has been observed that only a slight difference occured at ion implanted fabrics. The reason of this is implanted ion species do not cover and thicken the fibers. So, only a slight difference at WVP values may or may not perform on polyester fabrics. This results means, even after the implantation, polyester fabrics can still breath and will not disturb the user. This test proved us, MEVVA ion implantation has no harm for polyester fabrics. No success rate needed for water vapor permeability results due to WVP test has got it's own WVP Index.

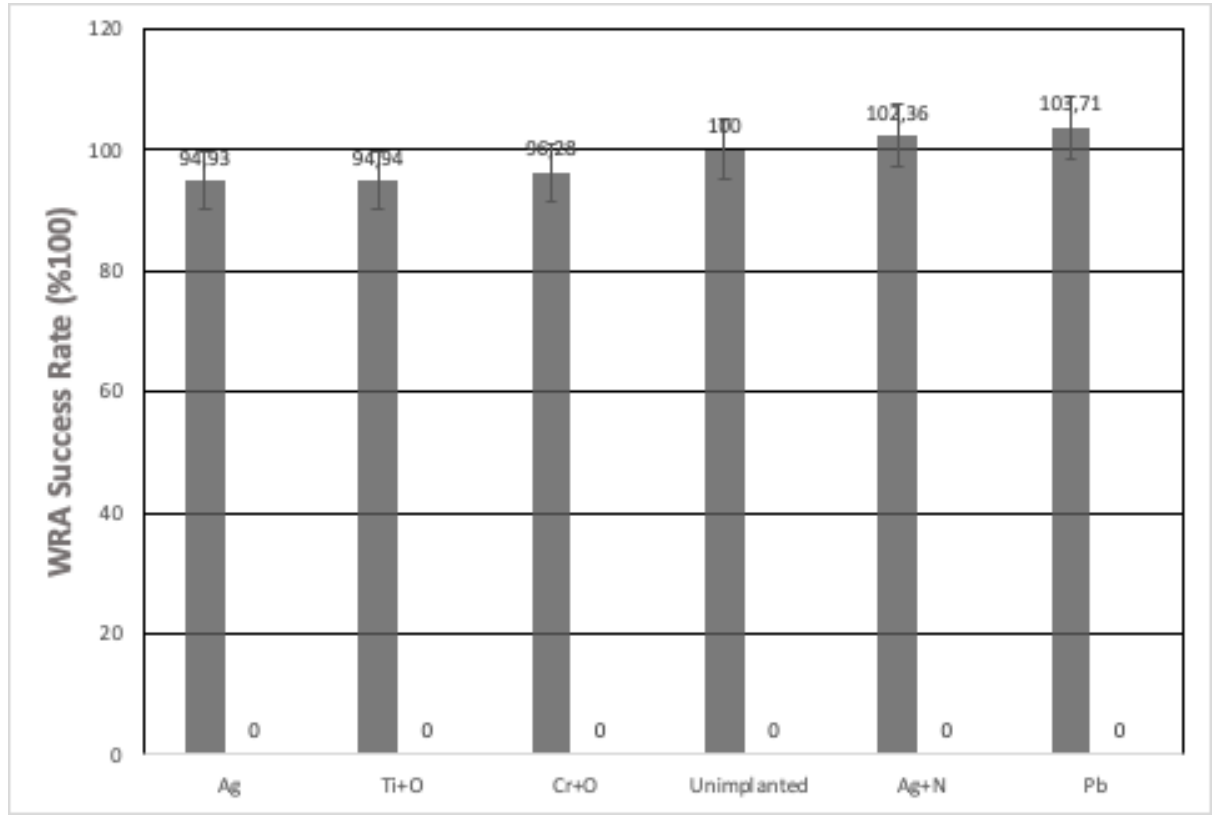

Figure 4. Wrinkle Recovery Angle (WRA) success rate results of ion implanted and unimplanted polyester fabrics.

When WRA tests resulted, it was noticed that all ion implanted polyester fabrics have almost same score with unimplanted one. Almost no difference seen in this test. This test proved that MEVVA ion implantation did not harden or loosen textile fibers. Because of this reason, all ion implanted polyesters could be able to present same wrinkle recovery angle performance with unimplanted polyester. 


\subsection{SUCCESS RATE OF ION SPECIES}

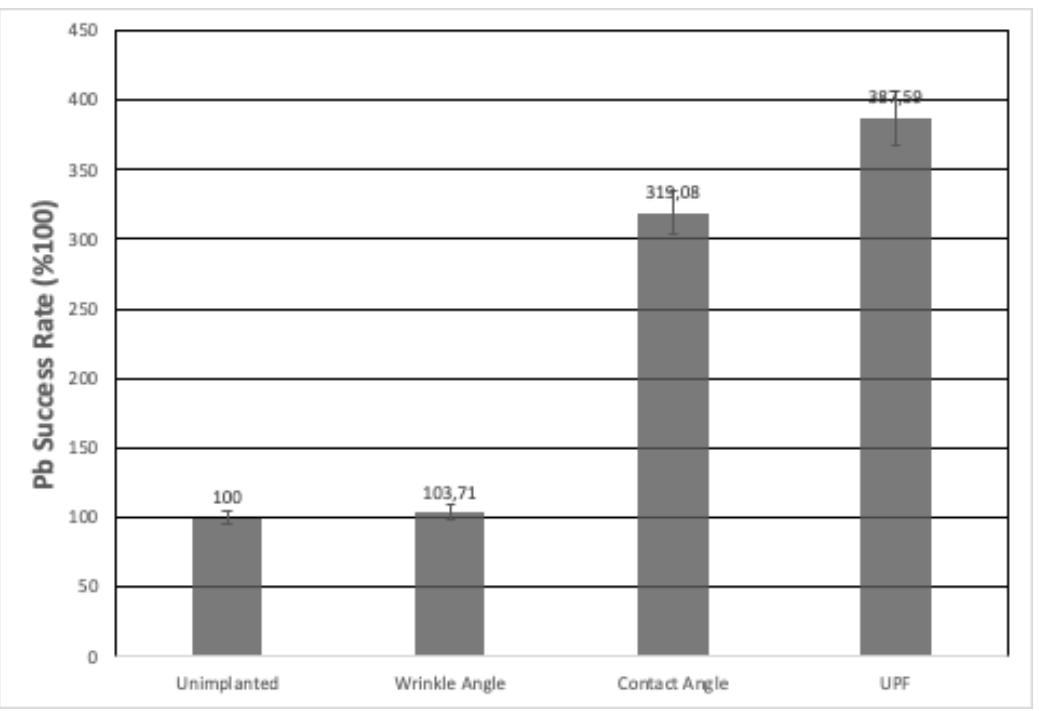

Figure 5. $\mathrm{Pb}$ success rate results at wrinkle recovery angle, contact angle and UPF tests. Water vapor permeability index result is $95 \%$.

While determining success rate of each ion species, just like the figures shown before, unimplanted polyester fabric had taken as a reference point and success of ion species were analysed according to that reference point.

In Figure 5, it can be seen that $\mathrm{Pb}$ succeded at much at UPF test. Also with same ion dose, $\mathrm{Pb}$ has presented very effective hydrophobia success rate which can be understood from contact angle test results. Finally it is seen that $\mathrm{Pb}$ has no harm for polyester fibers that can be analysed from wrinkle recovery angle and water vapor permeability index since if $\mathrm{Pb}$ implantation disordered the fibers of the fabric, wrinkle recovery angle would have been decreased or increased significantly. However, almost no change at wrinkle recovery angle was observed. This analyse can also rely on water vapor permeability index. No significant change was seen at that result too.

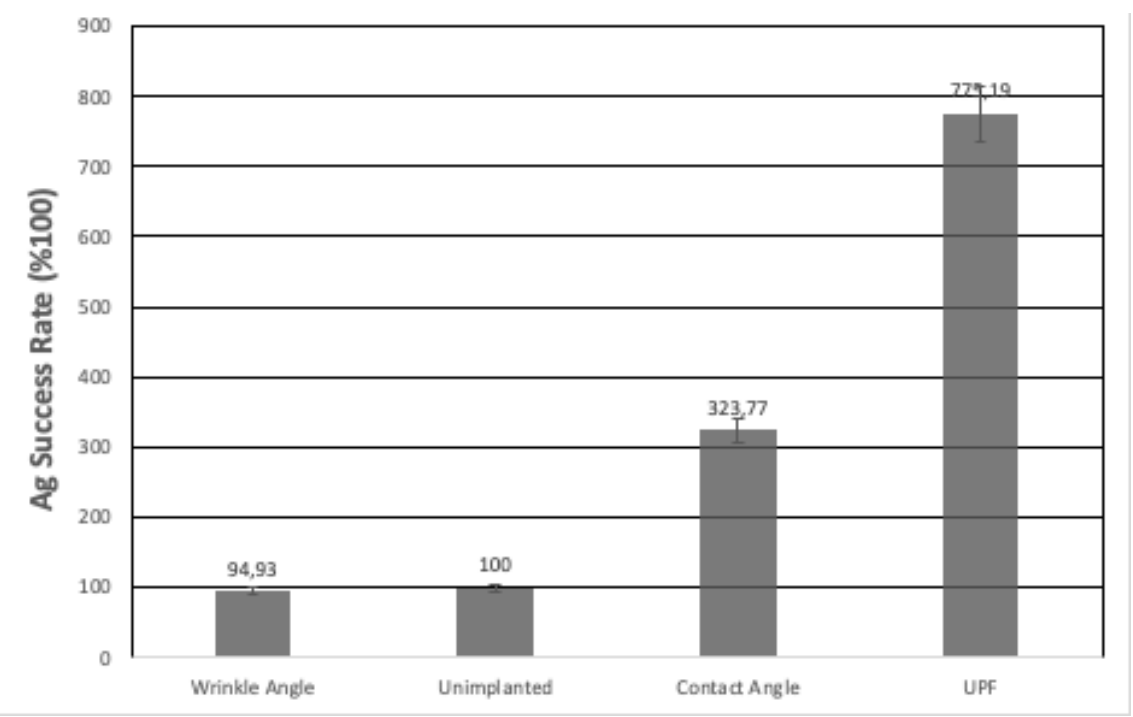

Figure 6. Ag success rate results at wrinkle recovery angle, contact angle and UPF tests. Water vapor permeability index result is $87,3 \%$ 
In Figure 6, it has been seen that, Ag has the most successful result of the study at UPF test. The UPF result of Ag implanted polyester was increased $775,19 \%$ when compared with unimplanted polyester. Also with same ion dose, contact angle results increased significantly. As a similar result to $\mathrm{Pb}$, no degredation at fibers was observed at polyester fabric. This can be analysed from both wrinkle recovery angle result and water vapor permeability index result. Almost no change was seen at both results. Further investigations will strengthen the results of this claim.

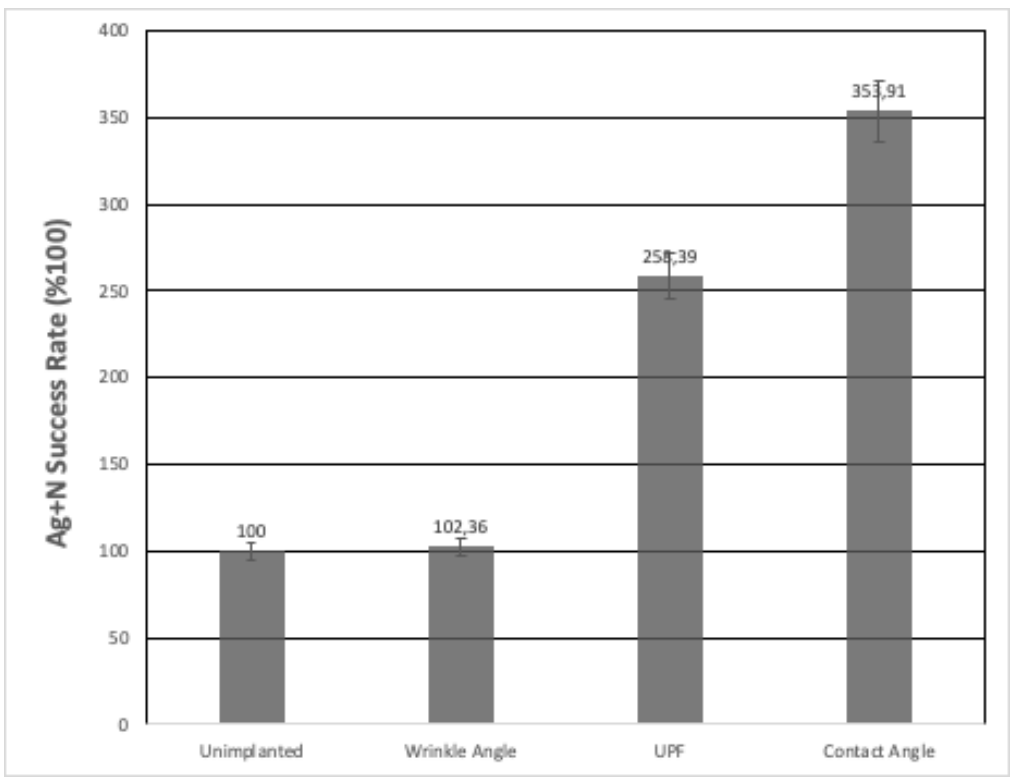

Figure 7. Ag+N success rate results at wrinkle recovery angle, contact angle and UPF tests. Water vapor permeability index result is $105 \%$

In Figure 7, Ag+N implantation was succeeded at contact angle test at much and also it showed high success at UPF test. No significance increase or decrease determined at both wrinkle recovery angle test and water vapor permeability test.

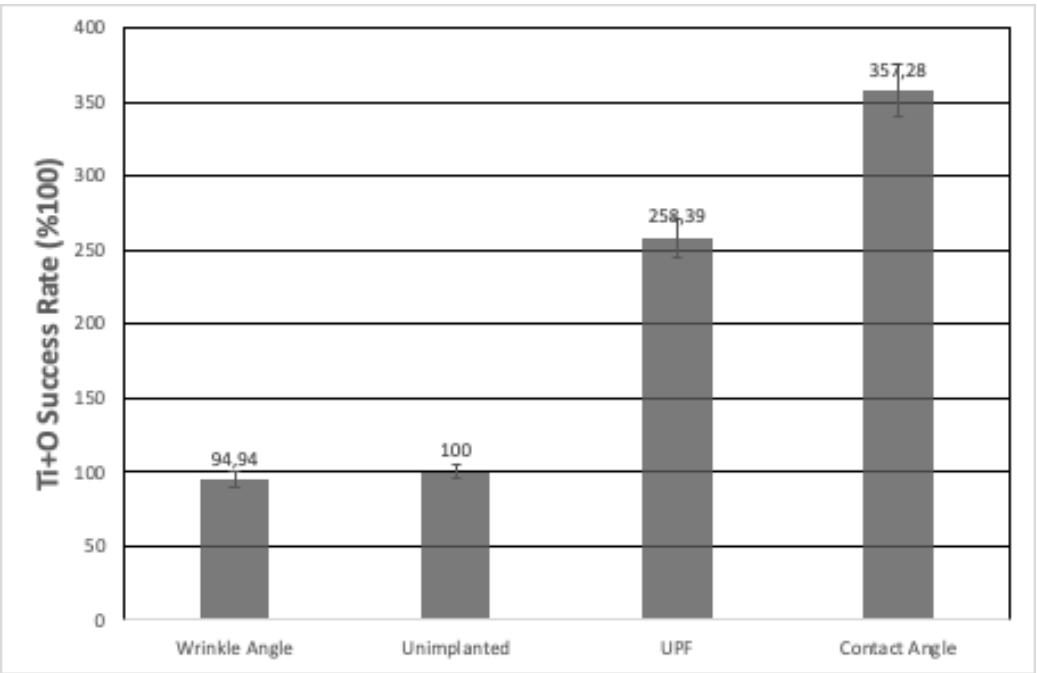

Figure 8. Ti+O success rate results at wrinkle recovery angle, contact angle and UPF tests. Water vapor permeability index result is $105 \%$. 
At Figure 8, Ti+O implantation presented it's most successful result at contact angle test. Also UPF test resulted with success. Just like $\mathrm{Pb}, \mathrm{Ag}, \mathrm{Ag}+\mathrm{N}$; $\mathrm{Ti}+\mathrm{O}$ did not resulted any degredation at polyester fabrics. This can be understood from wrinkle recovery angle and water vapor permeability index results.

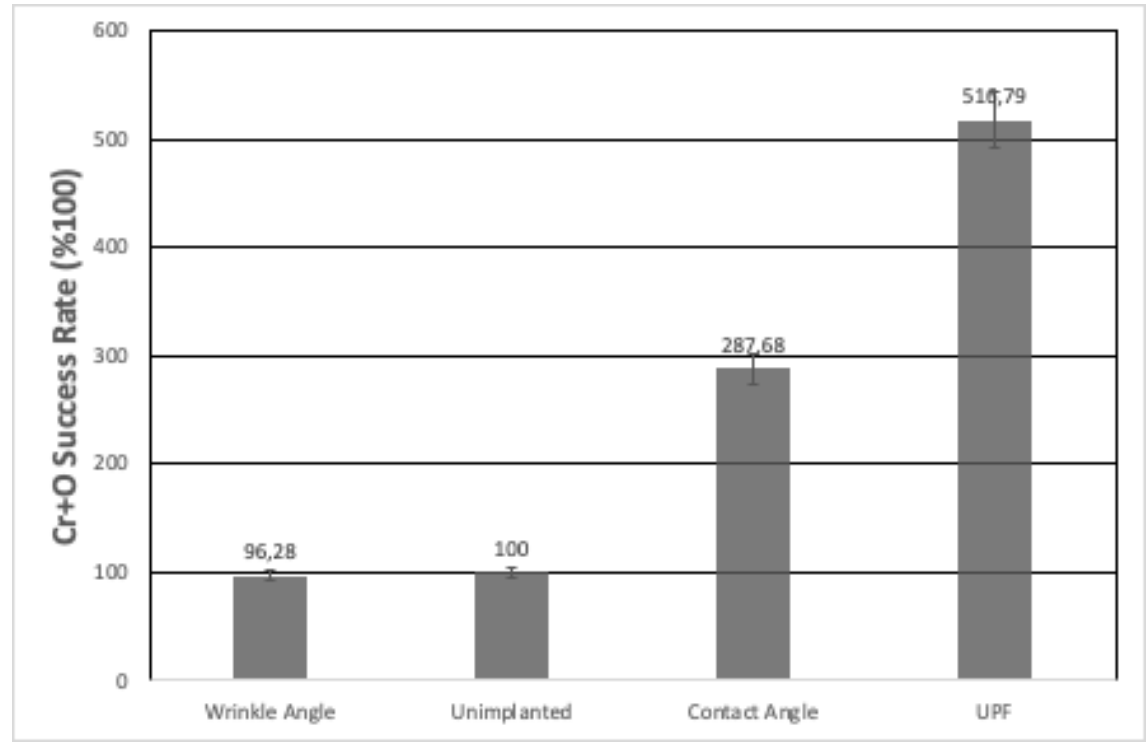

Figure 9. $\mathrm{Cr}+\mathrm{O}$ success rate results at wrinkle recovery angle, contact angle and UPF tests. Water vapor permeability index result is $90,7 \%$.

In Figure 9, $\mathrm{Cr}+\mathrm{O}$ implantation presented one of the highest result of the study at UPF Test. Also contact angle test resulted with success. No disorder was presented at polyester fabrics.

\section{CONCLUSION}

Polyester (PES) textiles are at a leading position in their share at textile industry therefore polyester fabrics was used at this study. In the first part of this study, UV Protection Factors and contact angle test results of implanted PES fabrics were investigated. In order to achieve this goal; $\mathrm{Pb}, \mathrm{Ag}, \mathrm{Ag}+\mathrm{N}, \mathrm{Ti}+\mathrm{O}$ and $\mathrm{Cr}+\mathrm{O}$ implanted to the PES fabrics with $5 \times 10^{16} \mathrm{ion} / \mathrm{cm}^{2}$ and their test results were compared with unimplanted PES fabric. The results of tests are promising. It has been seen that at both Contact angle test and UPF test, all ion implanted polyester fabrics presented distinctive success.

In the second part of the study, wrinkle recovery angle and water vapor permeability tests were done at PES fabrics to understand if there are any degredation formed on polyester fabrics after the ion implantation. Just like the first two tests; $\mathrm{Pb}, \mathrm{Ag}, \mathrm{Ag}+\mathrm{N}, \mathrm{Ti}+\mathrm{O}$ and $\mathrm{Cr}+\mathrm{O}$ implanted to the PES fabrics with $5 \times 10^{16} \mathrm{ion} / \mathrm{cm}^{2}$ and their WVP and WRA test results were compared with unimplanted PES fabric. At the end of these tests, It has been understood that almost no significant disorder formed at polyester fabrics after ion implantation.

There might be several questions asked about why some elements and compounds behave much different than the others. There are several theories about how these ions effect the chemical structures of the materials however the exact answers of the chemical pathways of surface modification are still unkonown up to date. Those answers can be research subjects of multiple other investigations. 
This study proved us great benefits of MEVVA ion implantation on polyester textile surfaces. In additionally, as a more important result, this study has presented that MEVVA ion implantation technique is not harmful for polyester textiles fibers.

The results of this study were partially published at some conferences [18-19] and based on several prior studies achieved by same group [20-21]. The results shared at this paper are much more extended version of those studies.

Similarly, several investigations based on the antibacterial efficiencies of $\mathrm{Ag}$ and $\mathrm{TiO}_{2}$ implantations by MEVVA are investigated deeply in another publication of the same group [22]. Therefore, those results are not included in this publication.

In addition, hopefully this study is aimed to strenghen the biomedical research achievements of the same group [23-28] and also be an important step at smart textile researches.

\section{ACKNOWLEDGMENT}

I would like to thank Mustafa Ahmet ÖZTARHAN for all the effort, supervision, equipment, and support he has provided for this research. Unfortunately, during the preparations of the manuscript, he passed away. May he rest in peace forever.

\section{CONFLICT OF INTEREST}

The author stated that there are no conflicts of interest regarding the publication of this article.

\section{REFERENCES}

[1] Öktem T, Tarakcığlu I, Özdoğan E, Öztarhan A, Namlıgöz ES, Karaaslan A, Tek Z. Modification of friction and wear properties of PET Membrane fabrics by MEVVA ion implantation. Materials Chemistry and Physics, 2008; 108: 208-213.

[2] Öktem T, Özdogan E, Namligöz S.E, Öztarhan A, Tek Z, Tarakçioglu I, Karaaslan A. TUBITAK Textile Research Center, Izmir, Investigating the Applicability of Metal Ion Implantation Technique (MEVVA) to Textile Surfaces, Textile Research Journal, 2006; 76: 32.

[3] Colwell JM, Wentrup-Byrne E, Bell JM, Wielunski LS. A study of the chemical and physical effects of ion implantation of micro-porous and nonporous PTFE. Surface and Coatings Technology, 2003; 168(2-3), 216-222.

[4] Cottin P, Lessard RA, Knystautas EJ, Roorda S. Polymer waveguides under ion implantation: optical and chemical aspects. Nuclear Instruments and Methods in Physics Research Section B: Beam Interactions with Materials and Atoms, 1999; 151(1-4), 97-100.

[5] Ge S, Wang Q, Zhang D, Zhu H, Xiong D, Huang C, Huang X, Friction and wear behavior of nitrogen ion implanted UHMWPE against ZrO2 ceramic. Wear, 2003; 255(7-12), 1069-1075.

[6] Huang N, Yang P, Leng YX, Wang J, Sun H, Chen JY, Wan GJ. Surface modification of biomaterials by plasma immersion ion implantation. Surface and Coatings Technology, 2004; 186(1-2), 218-226. 
[7] Karimi MV, Sinha SK., Kothari, D. C., Khanna, A. K., Tyagi, A. K. Effect of ion implantation on corrosion resistance and high temperature oxidation resistance of Ti deposited 316 stainless steel. Surface and Coatings Technology, 2002; 158, 609-614.

[8] Nakamura N, Hirao K, Yamauchi, Y. Tribological properties of silicon nitride ceramics modified by ion implantation. Journal of the European Ceramic Society, 2004; 24(2), 219-224.

[9] Sharkeev YP, Gritsenko BP, Fortuna SV, Perry AJ. Modification of metallic materials and hard coatings using metal ion implantation. Vacuum, 1999; 52(3), 247-254.

[10] Youssef AA, Budzynski P, Filiks J, Kobzev AP, Sielanko J. Improvement of wear and hardness of steel by nitrogen implantation. Vacuum, 2004; 77(1), 37-45.

[11] Yuguang W, Tonghe Z, Huixing Z, Xiaoji Z, Zhiwei D. Polymer modification by MEVVA source deposited and ion implantation. Surface and Coatings Technology, 2000; 131(1-3), 520-524.

[12] Zhang J, Wu Q, Yu X, Zha P, Li H. Effect of aging on the morphology and wettability of polytetrafluoroethylene. Materials Letters, 2001; 48(6), 362-368.

[13] Tonghe Z, Huixing Z, Changzhou J, Xiaoji Z, Yuguang W, Furong M, Jianzhong S. Industrialization of MEVVA source ion implantation. Surface and Coatings Technology, 2000; $128,1-8$.

[14] ASTM F2298 - 03(2009)e1 Standard Test Methods for Water Vapor Diffusion Resistance and Air Flow Resistance of Clothing Materials Using the Dynamic Moisture Permeation Cell.

[15] AATCC 128 Wrinkle Recovery of Fabrics: Appearance Method test methodology. American Association of Textile Chemists and Colorists technical manual.

[16] AATCC Test Method 183-2004 Transmittance or Blocking of Erythemally Weighted Ultraviolet Radiation through Fabrics. American Association of Textile Chemists and Colorists technical manual.

[17] AATCC 193-2004 Aqueous Liquid Repellency: Water/Alcohol Solution Resistance Test. American Association of Textile Chemists and Colorists, 01-Jan-2004.

[18] Öztarhan A, Akpek A, Oks E, Nikolaev A. Modifying textiles with antibacterial effect, friction resistance, UV protection and electrostatic charge decay abilities by an alternative nanotextile technology called MEVVA ion implantation technique. In Proceedings of the VIth Nanoscience and Nanotechnology Conference (NANOTR), 2010; 15-18.

[19] Akpek A. Surface modification of textiles by MEVVA Ion Implantation and providing UV protection and hydrophobia abilities. In Proceedings of the VIIIth International Fiber and Polymer Research Symposium, Eskisehir Osmangazi University, Turkey. 2021: 270.

[20] Öztarhan A, Akpek A, Oks E, Nikolaev A. Modifying medical textiles with antibacterial and friction resistance abilities by an alternative nanotextile technology called ion implantation technique. In 2010 15th National Biomedical Engineering Meeting IEEE, 2010: 1-4.

[21] Nikolaev AG, Savkin KP, Yushkov GY, Oks EM, Oztarhan A, Akpek A, Cireli I. Modification of the textile materials by vacuum arc ion source implantation. In Proceedings of the 10th 
International Conference on Modification of Materials with Particle Beams and Plasma Flows (10th CMM), Tomsk, Rusya, 2010: 19-24.

[22] Kizilkurtlu AA, Polat T, Aydın GB, Akpek A. Lung on a chip for drug screening and design. Current pharmaceutical design, 2018; 24: 5386-5396.

[23] Akpek A. Analysis of Surface Properties of Ag and Ti Ion-Treated Medical Textiles by Metal Vapor Vacuum Arc Ion Implantation. Coatings, 2021; 11(1), 102.

[24] Bulut S, Özçinar A, Çiftçioğlu Ç, Akpek A. A new algorithm for segmentation and fracture detection in X-ray images. In 2015 Medical Technologies National Conference (TIPTEKNO), IEEE. 2015:1-4.

[25] Akpek A, Youn C, Kagawa T. Temperature measurement control problem of vibrational viscometers considering heat generation and heat transfer effect of oscillators. In 2013 9th Asian Control Conference (ASCC), IEEE. 2013: 1-6.

[26] Çiftçioğlu Ç, Koçak O, Akpek A. Remote control of centrifuge and injection systems via MATLAB and ARDUINO. In 2015 Medical Technologies National Conference (TIPTEKNO), IEEE. 2015: 1-4.

[27] Ugar T, Kogak O, Akpek A. New concept design of an insulin pen for visually impaired or blind diabetius mellitus patients. In 2016 Medical Technologies National Congress (TIPTEKNO), IEEE. 2016: 1-4.

[28] Altinsu B, Koçak O, Akpek A. Design and analysis of an autoclave simulation using MATLAB/Simulink. In 2016 Medical Technologies National Congress (TIPTEKNO), IEEE. 2016: $1-4$. 